SVU- International Journal of Veterinary Sciences, 1 (2): 4-11, 2018.

Print ISSN: 2535-1826

Online ISSN: 2535-1877

Case Report

Open Access

\title{
Auricular Perichondritis and Multifocal Chondromata in an Egyptian Donkey with Droopy
} Ears: A Case Report

\begin{abstract}
Mohie Haridy 1, *, Abdelnasser A. Abdel-Hady ${ }^{2}$, and Soha A. Soliman ${ }^{3}$
${ }^{1}$ Department of Pathology and Clinical Pathology, Faculty of Veterinary Medicine, Faculty of Veterinary Medicine, South Valley University, Qena 83523, Egypt

${ }^{2}$ Department of Surgery, Anaesthesiology and Radiology, Faculty of Veterinary Medicine, South Valley University, Qena 83523, Egypt

${ }^{3}$ Department of Histology, Faculty of Veterinary Medicine, South Valley University, Qena, 83523, Egypt.

Abstract

A 9-years-old female Egyptian donkey presented with ear drooping, multiple subcutaneous firm nodules $(3-7 \mathrm{~mm})$ on the medial surfaces of both ears and intact skin. Furthermore, the ear pinnae were diffusely thickened with subcutaneous induration. The cartilaginous plates of the ear pinnae were intact. The nodular lesions consisted of chronic perichondritis and cauliflower-like outgrowths of hyaline chondrous tissue. Mononuclear inflammatory cells diffusely infiltrated in the subcutaneous tissue and involved the dermal papillae, the dermis and the margin of the cartilaginous outgrowths. Multifocal cauliflower-like chondrous outgrowths emerged from the inner surface of both ears and consisted of irregular lobules of hyaline cartilage with quite regular deeply basophilic chondrocytes and fibrous lobules. T-lymphocytes and macrophages diffusely infiltrated the dermis, and both T-cells and B-cells were densely infiltrated around newly-formed blood vessels in the subcutaneous tissue. On the basis of the gross, histopathological and immunohistochemical findings, chronic auricular perichondritis and multifocal chondromata were diagnosed for the first time in an Egyptian donkey.

Keywords: Auricular chondritis, Chondroma, Droopy ears, Equine, Perichondritis
\end{abstract}

Received: August 31, $2018 \quad$ Accepted: September 13, $2018 \quad$ Published: September 22, 2018 *Corresponding Author: Mohie Haridy

E-mail: mohieharidy@svu.edu.eg

Citation: Haridy et al. Auricular Perichondritis and Multifocal Chondromata in an Egyptian Donkey with Droopy Ears: A Case Report. SVU-IJVS 2018, 1 (2): 4-11.

Copyright: (C) Haridy et al. This is an open access article distributed under the terms of the creative common attribution license, which permits unrestricted use, distribution and reproduction in any medium provided the original author and source are created.

Competing interest: The authors have declared that no competing interest exists. 


\section{Introduction}

Auricular perichondritis is inflammation of the perichondrium, a layer of connective tissue that surrounds cartilage, and chondritis is inflammation of the auricular cartilage. Two major inflammatory conditions involve the auricular cartilage: suppurative perichondritis and relapsing polychondritis (RPC) (Venker-van Haagen, 2005). The most common causative agent of auricular perichondritis in dogs and cats is Pseudomonas. Auricular perichondritis may also follow inadequately treated auricular cellulitis, acute otitis externa, and accidental trauma or surgical trauma (Venker-van Haagen, 2005). In humans, injury to the ear typically causes auricular perichondritis. Piercing of the ear cartilage is the most significant risk factor. Other causes of injury include ear surgery, contact sports, burns, and acupuncture (Kaplan and Cook, 2004). Auricular perichondritis may lead to severe deformation of the pinna, if not treated vigorously. In dogs, the condition usually presents as a chronic disorder with very painful auricular perichondritis, chondritis, and cartilaginous ossification so that surgical removal of the auricle or the auricle and external ear canal is necessary (Venker-van Haagen, 2005). In equines, chondritis or chondropathy of the arytenoid cartilages of the larynx is a unilateral or bilateral disease that involves inflammation of the cartilage and adjacent structures and mucosa (Haynes et al., 1980). However, auricular perichondritis or chondritis has not yet been recognized in horses (Bowers and Slocombe, 2009). In a report of a crossbred Welsh Mountain Pony, auricular chondrosis presented as multiple thick, round, raised, nodular lesions on the medial aspects of both ears (Bowers and Slocombe, 2009). Extra-skeletal or soft tissue chondroma is a rare benign cartilaginous tumor that develops in the soft tissues without bone or joint involvement (Watanabe et al., 2012). Few cases of auricular chondroma have been recorded in humans (Kwon et al., 2010). Few cases of skeletal chondroma in dog, cat, cattle and sheep have been reported in the veterinary literature, and extra-skeletal chondroma has rarely been recorded (e.g., a pulmonary chondroma in a dog) (Patterson-Kane and Notenboom, 2004). To the best of our knowledge, auricular chondroma has not been recorded in animals. Chondroma is usually a solitary mass, but multifocal chondromata have been recorded in the trachea of humans (Heman-Ackah et al., 2002), in the periosteum in mice (Cantley et al., 2013), and in multifocal cartilaginous hamartomas in the lungs of cynomolgus monkey (Kaspareit et al., 2001). We report in this paper a case of auricular perichondritis and multifocal chondromata in an Egyptian donkey with drooping ears.

\section{Case report}

A 9-year-old female Egyptian donkey was admitted to the Clinic of Surgery of the Veterinary Teaching Hospital of South Valley University (Qena, Egypt). The animal had drooping of both ears since the previous 2 weeks (Fig. 1A). Multiple subcutaneous firm nodules $(3-7 \mathrm{~mm})$ were present on the medial surfaces of both ears. They were palpable below the surface of the skin without epidermal involvement (Fig. 1B). Furthermore, the ear pinnae were diffusely thickened with subcutaneous induration and intact skin (Fig. 1C). The cartilaginous plates of the ear pinnae were intact without any destruction. The lesions were not painful. The ears were neither hot nor erythematous. The food and water intake, alertness, and effort of the donkey were unchanged. The animal's respiratory rate and locomotion were as usual. The donkey's 6-month-old foal had no clinical abnormalities. The donkey was administered a general anesthetic using xylazine $(0.3 \mathrm{mg} / \mathrm{kg})$ and ketamine $(2.5 \mathrm{mg} /$ $\mathrm{kg}$ ). A punch biopsy was used to obtain 2 specimens from the inside surfaces of both ears. 


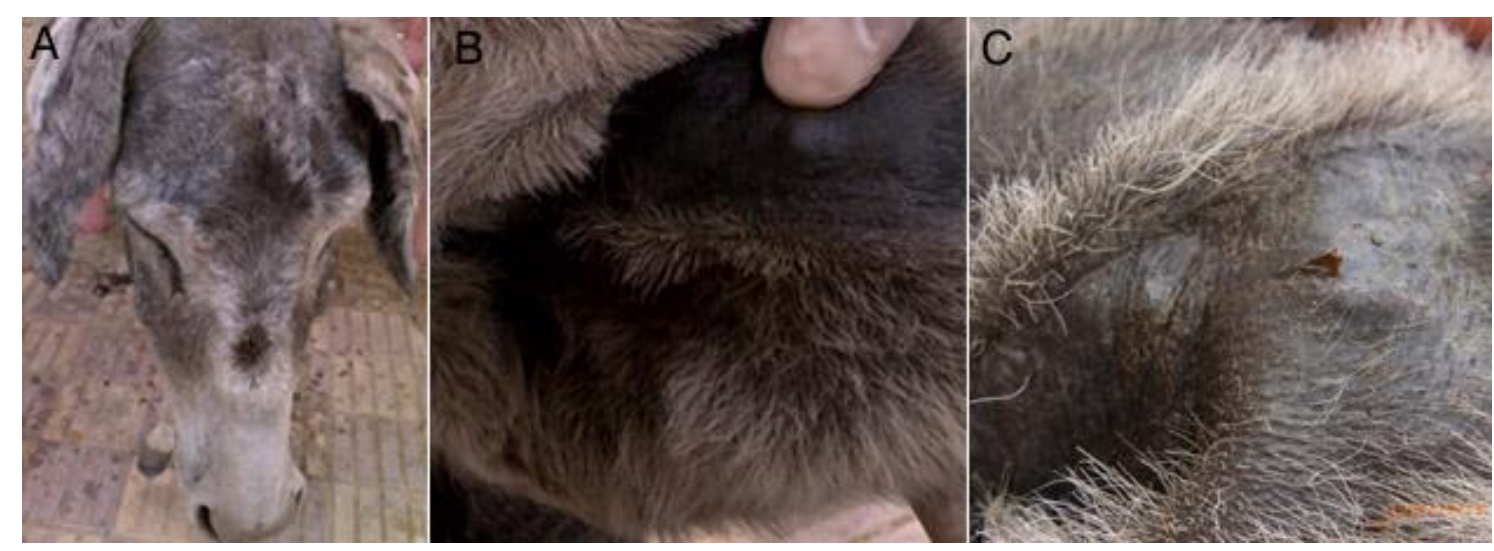

Fig. 1. Clinical signs of Auricular Perichondritis and Multifocal Chondromata in an Egyptian donkey: The clinical signs includes droopy ears (A), thickened ear pinnae with multiple subcutaneous firm nodules (3-7 mm) on the medial surfaces of the ears (B), and ear pinnae with subcutaneous induration and intact skin (close up of the base of the ear) (C).

Samples were fixed in $10 \%$ neutral buffered formalin and embedded in paraffin by routine methods. Sections measuring 4 microns thick were stained by hematoxylin and eosin. There was no epidermal change. The nodular lesions consisted of chronic perichondritis and cauliflower-like outgrowths of hyaline cartilaginous tissue (Fig. 2A). The subcutaneous tissue revealed pressure atrophy of the sebaceous gland and surrounding fibrous connective tissue near cartilaginous outgrowth. Mononuclear cells diffusely infiltrated in the subcutaneous tissue and involved the dermal papillae (Fig. 2B), subcutaneous collagenous fibers and margin of the cartilaginous outgrowths. The margin of a cartilaginous outgrowth degenerated where the mononuclear cells had heavily infiltrated it. Lymphocytes, plasma cells, and macrophages were moreover densely infiltrated around newly formed blood vessels in subcutaneous tissue (Fig. 2C). Pockets of lymphocytes, macrophages, and occasional melanin pigments were entrapped inside the cross section of the fibrochondrous outgrowths. No inflammatory cell infiltration was observed in the chondrous outgrowth and part of cartilaginous plate involved in biopsies. Multifocal cauliflower-like chondrous outgrowths emerged from the inner surface of both ears. The outgrowths consisted of irregular lobules of hyaline cartilage with quite regular deeply basophilic chondrocytes (Fig. 2D, E). Compared to normal hyaline cartilage, some lobules exhibited a more fibrous matrix that entrapped fibrous connective pockets containing lymphocytes, macrophages, and plasma cells. These lobules had transitioned to hyaline chondrous tissue (Fig. 2E). Sections of the samples were prepared for immunohistochemical staining. The labeled streptavidin-biotin complex technique was used to immunostain the cellular composition of the perichondritis. The following antibodies were used for immunohistochemistry: rabbit whole antiserum with reactivity to human T-cell CD3 peptide (Sigma-Aldrich, St. Louis, MO, USA), rabbit polyclonal antibody to CD20 antigen (Acris Antibodies $\mathrm{GmbH}$, Herford, Germany), and mouse monoclonal antibody to CD204 (i.e., antimacrophage scavenger receptor A; Cosmo Bio Co., Ltd., Tokyo, Japan). Antigens were retrieved by steaming the specimens in an antigen retrieval solution (Dako, Glostrup, Denmark) for 15 minutes at $121^{\circ} \mathrm{C}$. 


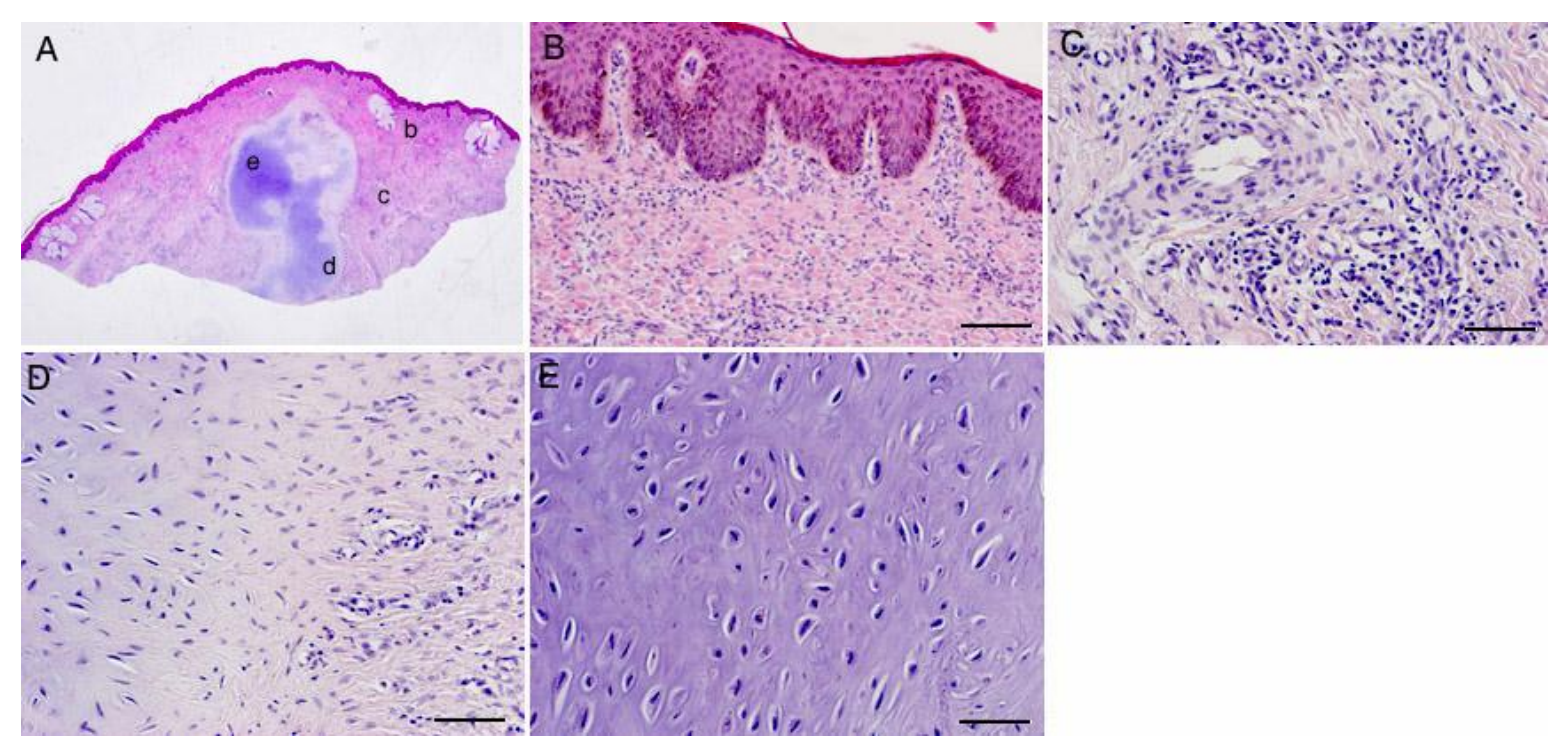

Fig. 2. Histopathological findings of auricular chondromata associated with chronic perichondritis in an Egyptian donkey: (A) Sub-gross section revealed cauliflower-like outgrowth of chondrous tissue consistent with chondroma. The surrounding subcutaneous tissue was diffusely infiltrated with mononuclear cells and the overlying skin was intact. Note, atrophy of sebaceous gland occurred near chondrous outgrowth. (B) The subcutaneous tissue was diffusely infiltrated by chronic mononuclear cells in the dermal papillae, collagenous fibers and margin of chondrous outgrowth. (C) Lymphocytes, plasma cells and macrophages were densely infiltrated around newly-formed blood vessels. (D, E) The outgrowths were hyaline chondrous tissue with quite regular deeply basophilic chondrocytes. Bras = $200 \mu \mathrm{m}(\mathrm{A}), 50 \mu \mathrm{m}(\mathrm{B}), 100 \mu \mathrm{m}(\mathrm{C})$ and $50 \mu \mathrm{m}(\mathrm{D})$.

The specimens were then immunolabeled using the Dako REAL Envision Detection System Peroxidase/DAB+, Rabbit and Mouse Detection System (Dako, Glostrup, Denmark) in accordance with the manufacturer's instructions. Most mononuclear cells were CD3-positive Tcells, which were diffusely distributed in the subcutaneous tissue and densely

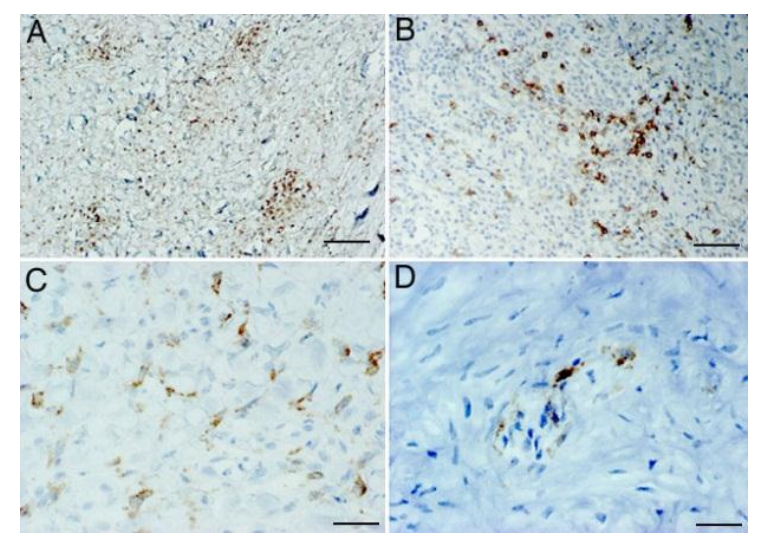

aggregated around newly formed vessels (Fig. 3A) and at the margin of the chondrous proliferation. The CD20-positive B-cells were focally aggregated around newly formed blood vessels (Fig. 3B) and were diffusely present in the dermal papillae. The CD204 macrophages were diffusely infiltrated in subcutaneous tissue (Fig. 3C) and entrapped in the pockets of the fibrochondrous outgrowths (Fig. 3D).

Fig. 3. Immunohistochemical staining of chronic auricular perichondritis in an Egyptian donkey: The CD3-positive T-cells are diffusely distributed in the subcutaneous tissue and densely aggregated around newly formed vessels (A). The CD20-positive B-cells are focally aggregated around newly formed blood vessels (B). The CD204-positive macrophages are diffusely infiltrated in the subcutaneous tissue (C), and are entrapped in the pockets of fibrous connective tissue within the chondrous lobules (D). Bars $=200 \mu \mathrm{m}$ (A) and $50 \mu \mathrm{m}(\mathrm{B}-\mathrm{D})$. 


\section{Discussion}

Based on the gross, histological, and immunohistochemical findings, chronic auricular perichondritis associated with multifocal chondromata was diagnosed in an Egyptian donkey with droopy ears in the present study. In equines, neither auricular perichondritis/chondritis nor auricular chondroma has been reported. Auricular chondrosis in a Welsh Mountain Pony was limited to the auricular cartilage without epidermal and dermal changes, and lesions consisted of irregular central areas of degeneration and lysis with deposition of the cartilage along the margins. The cartilage plate was greatly thickened and had no chondrocytes located centrally where they were replaced with adipose tissue and newly formed blood vessels. Inflammation was not recognized (Bowers and Slocombe, 2009). In the present case, diffuse mononuclear cell infiltration in the dermis and chondrous proliferation without degeneration and lysis were present, which did not match the lesions of chondrosis. Furthermore, chronic chondritis of the arytenoid cartilage in horses shows marked lamination by fibrous connective tissue, which was not observed in the cartilage of the ear in the donkey (Haynes et al., 1980). Auricular chondropathy in 2 Swiss Braunvieh heifers was recently characterized by bilateral thickening of the base of the ears, ear canal occlusion, and ear drooping. A cartilaginous plate with twice the normal thickness and divided centrally by a massive fibrous tissue may be regenerative changes occurring after degeneration by an inflammatory process (Bleul et al., 2006). Some Swiss Braunvieh cattle with pinnae malformations have a shortened and thickened epiglottis and malformations of the arytenoid cartilage. In most animals, the elastic cartilage is replaced by fibrocartilage and hyaline cartilage (Bleul et al., 2011). The degenerative changes recorded in these cattle were not like inflammatory and proliferative changes in the present case. Furthermore, the affection of other cartilages in the donkey could not be observed. Human RPC is an episodic, immune-mediated disease with a progressive course of inflammation and destruction of auricular and non-auricular cartilaginous structures such as nasal, tracheal, and joint cartilages (Puechal et al., 2014). In the donkey, signs of affection in other cartilaginous tissues such as respiratory distress and locomotion disorders were not observed. The donkey was working, eating, and drinking as usual. Feline RPC is almost limited to the auricular cartilage and is characterized by ear swelling, erythema, pain, and curling (Gerber et al., 2002) and by degeneration and loss of basophilic staining and necrosis of the ear cartilage. Mononuclear and polymorph-nuclear cell infiltration, perichondral and perivascular fibrocyte and capillary endothelial cell proliferation, and granulation have moreover been observed in the dermis (Baba et al., 2009). The clinical signs RPC in felines such as swelling, heat, pain, and redness of the ears are different from the signs in the donkey and were completely absent in the current case. Furthermore, the cartilaginous plate in the cat is almost destroyed and fragmented and is replaced by granulation tissue and chondrous fragment proliferation that results in deformity of the ear (Paterson and Tobias, 2013). These changes were not observed in the donkey and the cartilage plate was intact and ears were not deformed. Perichondral and perivascular fibroblast and capillary endothelial cell proliferation were similarly observed in the present study; however, its exact pathogenesis is not understood. Auricular chondritis has 
been reported in experimental rats (Kitagaki et al., 2003; Prieur et al., 1984) and mice (Kitagaki and Hirota, 2007) and has been induced in these species as a model for type 2 collagen autoimmune disease in humans (Prieur et al., 1984). By contrast, antibodies against type 2 collagen have not been demonstrated in spontaneous auricular chondritis and only auricular cartilage is involved (Kitagaki and Hirota, 2007; Kitagaki et al., 2003). Cage trauma and metal ear tags are suspected as the inciting causes of auricular chondritis in rats and mice, but the disease sometimes occurs without a history of trauma. Auricular chondritis is always bilateral-even in ears with no metal ear tag-and its incidence is increased in aged rats and mice (Kitagaki and Hirota, 2007; Kitagaki et al., 2003). A firm, multi-nodular to diffuse thickening of the pinnae extend from the base to the periphery; however, diffuse thickening without nodules sometimes occur. Degeneration and lysis of the auricular cartilage plate with granulomatous inflammation have been recorded. Proliferative immature cartilaginous nodules and fibrosis and osseous metaplasia occur later. The dermis and epidermis are histologically normal (Chiu and Lee, 1984; Kitagaki and Hirota, 2007; Kitagaki et al., 2003). The bilateral involvement of ears, multinodular thickening of the pinnae, chronic inflammation, chondrous proliferation in the present study are similar for those recorded in rats and mice. However, there was no destruction of the auricular cartilage and not inflammatory cell infiltration in the cartilaginous plate. Lesions in the donkey moreover involved the dermis, whereas epidermis was normal; this is in contrast to the lesions in rat and mice in which the dermis and epidermis are not involved. The cellular constituents of chronic perichondritis were T-lymphocytes predominately, B-lymphocytes and macrophages. These cells were similarly observed in auricular chondritis in metal ear-tagged C57BL/6 mice (Kitagaki and Hirota, 2007). Two hypotheses have emerged to explain fibrosis, osseous metaplasia and chondrous proliferative nodules (Chiu and Lee, 1984). In the first hypothesis, cartilage degeneration and cartilaginous plate splitting induces perichondral fibrous proliferation, which invades into the degenerated areas and differentiates into fibroadipose tissue and progresses to fibrochondrous and/or osteochondrous tissue (Prieur et al., 1984). In the second hypothesis, focal granulomatous inflammation is not accompanied by chondrolysis. As the inflammation progressively destroys the cartilage, fibroblasts proliferate within granulomas and differentiate into fibrochondrous, chondrous, and osseous tissues. The inflammation eventually subsides, and the cartilage plate is replaced by nodular masses of fibrochondrous or osteochondrous tissue, as described in the first hypothesis (Kitagaki et al., 2003). Kitagaki et al. (2003) suggest that cartilaginous nodules are formed by the proliferation of chondrocytes entrapped in the interstitium after destruction of the cartilaginous plate due to severe granulomatous lesions. Chronic inflammation accompanied by ear tagging probably initiates auricular lesions. By contrast, Prieur et al. (1984) suggest that the mesenchymal cells in the perichondrium are the source of the chondrogenic cells for proliferative nodules. In the present case, severe fibrosis around the cartilaginous outgrowth with chronic inflammatory cell infiltration but no destruction of the auricular cartilaginous plate suggested that the origin of the chondromata was fibroblastic proliferation (as described in 
the second hypothesis). Furthermore, no ear tags were used in the donkey, but traumatic causes could not be excluded. In rats and mice, fibrovascular nodules can progress to fibrochondrous, osteochondrous, or osseous metaplasia. Fibrochondroma, chondroma, and osteosarcoma could be differentiated easily by the absence of chronic inflammation (Chiu and Lee, 1984). Ear tags containing cadmium chloride induce benign or malignant tumors (e.g., compound osteosarcoma, fibrosarcoma, giant cell tumor, and histiocytic sarcoma) that develop after chondritis (Waalkes et al., 1987). Three hypotheses for the origin of extraskeletal chondroma are (1) migration of cartilage cells of the skeleton to the adjacent connective tissue, (2) conversion of ligamentous pre-cartilaginous tissue during the activation period, and (3) metaplasia of synovial cells that differentiate to cartilaginous cells (Kwon et al., 2010). In the donkey, multifocal chondromata were identified in both ears. Multifocal chondromata have been reported as extraskeletal chondroma in the human trachea (Heman-Ackah et al., 2002); however, they have never been reported in animals, except as chondrous hamartoma in the lungs of the cynomolgus monkey (Kaspareit et al., 2001).

\section{Conflict of Interests}

The authors have no potential conflicts of interest to declare with respect to the research, authorship, and/or publication of this article.

\section{Funding}

The authors received no financial support for the research, authorship, and/or publication of this article.

\section{References}

Baba T, Shimizu A, Ohmuro T, Uchida N, Shibata K, Nagata M, Shirota K (2009). Auricular chondritis associated with systemic joint and cartilage inflammation in a cat. The Journal of Veterinary Medical Science, 71: 79-82.

Bleul U, Ahrens E, Stranzinger G, Sydler T, Ohlerth S, Braun U (2006). Auricular chondropathy in two Swiss Braunvieh heifers. The Veterinary Record, 159: 890-892.

Bleul U, Stranzinger G, Sydler T (2011). Polychondritis: a new disease in Swiss Braunvieh. Schweizer Archiv fur Tierheilkunde, 153: 526-529.

Bowers JR, Slocombe RF (2009). Auricular chondrosis in a horse. Australian Veterinary Journal, 87: 219-221.

Cantley L, Saunders C, Guttenberg M, Candela ME, Ohta Y, Yasuhara R, Kondo N, Sgariglia F, Asai S, Zhang $\mathrm{X}$, Qin L, Hecht JT, Chen D, Yamamoto M, Toyosawa S, Dormans JP, Esko JD, Yamaguchi Y, Iwamoto M, Pacifici M, Enomoto-Iwamoto M (2013). Loss of beta-catenin induces multifocal periosteal chondroma-like masses in mice. The American Journal of Pathology, 182: 917-927.

Chiu T, Lee KP (1984). Auricular chondropathy in aging rats. Veterinary Pathology, 21: 500-504.

Gerber B, Crottaz M, von Tscharner C, Scharer V (2002). Feline relapsing polychondritis: two cases and a review of the literature. Journal of Feline Medicine and Surgery, 4: 189194.

Haynes PF, Snider TG, McClure JR, McClure JJ (1980). Chronic chondritis of the equine arytenoid cartilage. Journal of the American Veterinary Medical Association, 177: 1135-1142.

Heman-Ackah YD, Sataloff RT, Goldstein S, Heman-Ackah SE, Ghabra M (2002). Multifocal tracheal chondromata. Journal of Voice, 16: 587-591.

Kaplan AL, Cook JL (2004). The incidences of chondritis and 
perichondritis associated with the surgical manipulation of auricular cartilage. Dermatologic Surgery, 30: 58-62.

Kaspareit J, Friderichs-Gromoll S, Buse E, Korte R, Vogel F (2001). Spontaneous pulmonary neoplasms in cynomolgus monkeys (Macaca fascicularis): a report of two cases. Experimental and Toxicologic Pathology, 53: 267-269.

Kitagaki M, Hirota M (2007). Auricular chondritis caused by metal ear tagging in C57BL/6 mice. Veterinary Pathology, 44: 458-466.

Kitagaki M, Suwa T, Yanagi M, Shiratori K (2003). Auricular chondritis in young ear-tagged Crj:CD(SD)IGS rats. Laboratory Animals, 37: 249-253.

Kwon H, Kim HY, Jung SN, Sohn WI, Yoo $\mathrm{G}$ (2010). Extraskeletal chondroma in the auricle. The Journal of Craniofacial Surgery, 21: 1990-1991.

Paterson S, Tobias K (2013). Atlas of Ear Diseases of The Dog and Cat. WileyBlackWell Oxford, UK.

Patterson-Kane JC, Notenboom AR (2004). Pulmonary chondroma in a dog. The Veterinary Record, 155: 59-60.

Prieur DJ, Young DM, Counts DF (1984). Auricular chondritis in fawn-hooded rats. A spontaneous disorder resembling that induced by immunization with type II collagen. The American Journal of Pathology, 116: 69-76.

Puechal X, Terrier B, Mouthon L, Costedoat-Chalumeau N, Guillevin L, Le Jeunne C (2014). Relapsing polychondritis. Joint, Bone, Spine: Revue Du Rhumatisme, 81: 118-124.

Venker-van Haagen A (2005). Ear, Nose, Throat, and Tracheobronchial Diseases in Dogs and Cats. SchlüterscheVerlagsgesellschaftmbH \& Co. KG, Hans-Böckler-Allee 30173 Hannover Germany, 7: 23-24.

Waalkes MP, Rehm S, Kasprzak KS, Issaq HJ (1987). Inflammatory, proliferative, and neoplastic lesions at the site of metallic identification ear tags in Wistar [Crl:(WI)BR] rats. Cancer Research, 47: 2445-2450.

Watanabe F, Saiki T, Ochochi Y (2012). Extraskeletal chondroma of the preauricular region: a case report and literature review. Case Reports in Medicine, 2012: Article ID 121743, 4 pages. 